\title{
UTILIZATION OF PLC PROGRAMMING FOR GRAVITY DIE CASTING AUTOMATION
}

\author{
Ishrat Meera Mirzana ${ }^{1}$, Narjis $B^{2}$, K Vishnu Prashant Reddy ${ }^{3}$ \\ ${ }^{1}$ Associate Professor, Mechanical Engineering Dept., Muffakham Jah College of Engg \& Tech, Telangana, India \\ ${ }^{2}$ Assistant Professor, Instrumentation Engineering Dept., Muffakham Jah College of Engg \& Tech, Telagana, India \\ ${ }^{3}$ Student, Mechanical Engineering Dept., Muffakham Jah College of Engg \& Tech, Telangana, India
}

\begin{abstract}
Under the present regime of globalization and liberalization, quality enhancement and cost reduction are two major steps to enhance productivity in major Industries. We focused on the very practical, safe, economical and rewarding strategies i.e. the application of LOW COST AUTOMATION. In Industry which uses of automation, a sequence is followed in the manufacturing of number of products of the same kind and thus chance for Automation. In our research we have achieved low cost automation through a Programmable Logic Controller (SIEMENS SIMANTIC S7300PLC with STEP7 software). It is used to replace the necessary sequential relay circuits for the control on the devices. In automated system, PLC is usually the central part of the control system. With execution of a program stored in program memory, PLC continuously monitors status of the system through signals from input devices (sensors). Based on the logic implemented in the program PLC determines which action is to be executed with output instruments Actuators). Depending on our requirement Pneumatic actuators, Solenoid valves and sensors are used to run the sequence. Flow control valves are used to regulate the flow of air pressure where ever necessary.
\end{abstract}

Keywords: Automation, Programmable logic controller, Gravity die casting.

\section{INTRODUCTION}

In the recent past, Automation techniques have become one of the effective strategies in the modern manufacturing process to get multifarious benefits. Thus, it is necessary that industries explore methods of enhancing automation and thereby increase the productivity to acquire greater competitiveness in the market. Automation replicates human effort through the introduction of machines and increases the productivity by utilizing available resources in the most efficient manner. In other words, automation is a technology concerned with the application of mechanical, electronic and computer based systems to operate and control production.

For rapid industrial growth in developing countries like India, Brazil etc, which is a nucleus of small industries, automation plays an important role[2]. The electronic age and the automatic age both of which were required as revolutions in industrial production is now substituted by Automation age. Fixed automation, Programmable automation and Flexible automation are the three types of automations. Due to high initial investment for custom engineering equipment and major batch manufacturing requirements, need for low cost programmable automation increased[3]. The LCA techniques are considered to be one of the most commendable ones in solving various problems related to automation as it creates some degree of automation around the existing equipment, tools and methods using mostly the standard equipment available in the market. This can be done by introducing very simple devices such as limit switches, Electrical relays, Solenoid valves and pneumatic actuators. Hence, the use of simple devices utilizing relatively cheap human effort in certain operations is called Low Cost Automation. Because of various reasons, the relay logic systems are widely used in the industrial automation systems till recent past. But with the advent of microcontrollers the Automation systems using them as controllers are increasing day by day. Programmable logic controller is one such microcontroller whose popularity is increasing very rapidly. A PLC may be used to control the fluid power more efficiently[5]. A programmable logic controller uses a program to link together a number of input devices (e.g. Sensors, switches) and output devices (e.g. Actuators, LED's) to produce a desired sequence of operations. To perform these functions automatically, activities such as Unloading, Feeding, Clamping, Welding, Forming, Gauging, Sorting, Drilling, Cutting, Packing, Printing, Loading etc should be subjected to Low Cost Automation system adoption.

Mohan, et.al., [1] have carried out low cost automation of fruit packing and exporting unit. Ahuja, et.al.,[4] utilized programmable controller (PLC) and bar-code reader, which have advantages of generality and wide application results in industries as well as low-cost, and constructed a low-cost automation system of valve switching operation. Different studies and works have been carried out to utilize low cost automation methodology using PLC programming $[7,8,9,10,11]$. Less focus has been on automating the conventional gravity die casting process, thus, the current work focused on gravity die casting process which is a complex process that requires constant monitoring of parameters for the production of quality products. 


\section{LOW COST AUTOMATION OF GRAVITY} DIE CASTING USING PLC PROGRAMMING

In order to overcome the hurdles of manual methods and to increase the productivity rate, we applied the application of this Low cost automation to a Gravity die casting set up using PLC PROGRAMMING .It offers improved quality consistent processing, better equipment utilization, higher productivity with reduced labor, cleaner work environment , time saving and overall cost saving .For the above casting process we are using seven pneumatic cylinders, two pneumatic grippers, one pneumatic rotary actuator. All the cylinders used are double acting cylinders. These 10 cylinders are equipped with double and single solenoid valves and PLC panel.

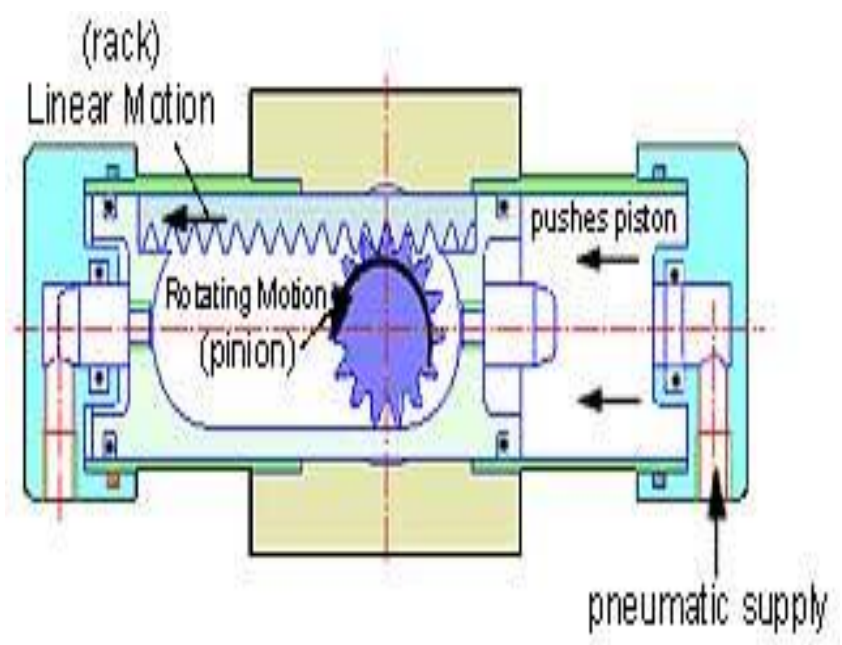

Fig.1 Set up of gravity die casting for automation

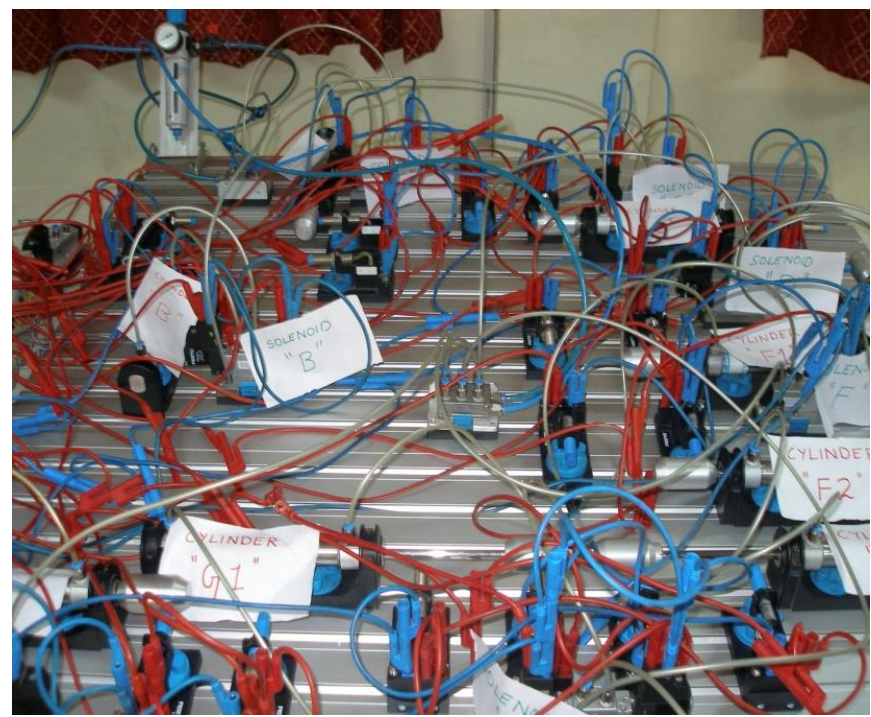

Fig2. PLC Relay set up

\subsection{Functional Cycle}

The Cylinder A pushes the cylinder B wherein cylinder B slides on the mild steel guide way, cylinder B lifts the crucible. Then pneumatic gripper $\mathrm{C}$ is actuated and crucible is gripped, rotary actuator D is activated and molten metal poured into the die (conversion of linear motion to rotary motion). The pinion of actuator is connected to the shaft of the gripper. Pouring of molten metal is controlled with the help of a Flow control valve fitted to the rotary actuator. Then De-activation of rotary actuator takes place and crucible comes back to its original position. Also pneumatic gripper $\mathrm{C}$ is deactivated and gripping action is released. Cylinder B brings down the crucible and cylinder A pulls back cylinder B. Now timer is activated and time allotted for solidification of molten metal. Forward stroke of Cylinder $\mathrm{E}$ occurs and gripper $\mathrm{H}$ is fitted to the end of the piston of cylinder E. Pneumatic gripper $\mathrm{H}$ is actuated is also activated and it grips the core area. Reverse stroke of cylinder $\mathrm{E}$ lifts the core and cylinder $\mathrm{F}$ is actuated which ejects the pins. Cylinders $G$ are activated and both the cylinders are operated using a single solenoid. Their function is to separate the die halves. Timer is activated and cast is ejected, cylinder $\mathrm{G}$ closes the die halves. Now cylinder $\mathrm{E}$ is actuated, forward stroke of cylinder $\mathrm{E}$ places the core back. Pneumatic gripper $\mathrm{H}$ is deactivated and core is released and return stroke of cylinder $\mathrm{E}$ occurs, which complete one cycle of functionality.

It is required to find out the dimensions of cylinders required for the cycle of operation and also the time taken for one complete cycle.

It is required to find out the dimensions of cylinders required for the cycle of operation and also the time taken for one complete cycle.

\section{Cylinder A:}

Cylinder A pushes a weight of $40 \mathrm{~kg}$ on dovetail guide ways $\mathrm{Pa}=14.7 \mathrm{psi}$

$\mathrm{P}=6 \mathrm{bar}=87 \mathrm{psi}=0.6 \mathrm{~N} / \mathrm{mm}^{2}$

$\mathrm{FAD}=\mathrm{Q}=1.179 \mathrm{inch} / \mathrm{sec}$

$\mathrm{L}=300 \mathrm{~mm}=11.81 \mathrm{in}$

Force $=40 * 9.81=392.4 \mathrm{~N}$

Thrust force $\mathrm{P}=1.5 * \mathrm{~F}=1.5 * 392.4=588.6 \mathrm{~N}$

$$
\begin{gathered}
\mathrm{P}=\Pi / 4 * \mathrm{D} * \mathrm{~d} * \mathrm{p} \\
588.6=\Pi / 4 * \mathrm{D} * \mathrm{D} * 0.6
\end{gathered}
$$

$\mathrm{D}=35.34 \mathrm{~mm}=$ say $38 \mathrm{~mm}=1.4 \mathrm{in}$

$\mathrm{D}=2 \mathrm{~d}, 1.4=2 * \mathrm{~d}$

$\mathrm{d}=0.7$ in

Forward stroke Tfs $=\underline{0.00186 * \mathrm{~L} * \mathrm{D} * \mathrm{D} *(\mathrm{P}+\mathrm{Pa})}$ $\mathrm{Q}$

$$
\begin{gathered}
=\underline{0.00186 * 11.81 * 1.4 * 1.4 *(87+14.7)} \\
=2.16 \mathrm{sec}
\end{gathered}
$$

$$
\begin{aligned}
& \text { Where } \\
& \begin{array}{ll}
\mathrm{P} & =\text { SUPPLY LINE PRESSURE } \\
\mathrm{Pa} & =\text { ATMOSPHERIC PRESSURE } \\
\mathrm{FAD} & =\text { FREE AIR DISCHARGE } \\
\mathrm{D} & =\text { CYLINDER BORE DIAMETER } \\
\mathrm{d} & =\text { PISTON ROD DIAMETER } \\
\mathrm{L} & =\text { LENGTH OG THE STROKE } \\
\mathrm{Tfs} & =\text { TIME TAKEN FOR FORWARD STROKE } \\
\mathrm{Trs} & =\text { TIME TAKEN FOR RETURN STROKE }
\end{array}
\end{aligned}
$$




\section{Cylinder B:}

Cylinder B has to lift a weight of $30 \mathrm{~kg}$

$\mathrm{L}=150 \mathrm{~mm}=5$.9in

Force $\mathrm{F}=30 * 9.81=294.3 \mathrm{~N}$

Thrust force $\mathrm{P}=1.5 * 294.3=441.45 \mathrm{~N}$

$\mathrm{P}=\Pi / 4 * \mathrm{D} * \mathrm{~d} * \mathrm{p}$

$441.45=\Pi / 4 * \mathrm{D} * \mathrm{D} * 0.6$

$\mathrm{D}=30.06 \mathrm{~mm}=\mathrm{say} 32 \mathrm{~mm}=1.25 \mathrm{in}$

$\mathrm{D}=2 \mathrm{~d}$

$32=2 * \mathrm{~d}$

$\mathrm{d}=16 \mathrm{~mm}=0.625 \mathrm{in}$

$\mathrm{Tfs}=\frac{0.00186 * \mathrm{~L} * \mathrm{D} * \mathrm{D} *(\mathrm{P}+\mathrm{Pa})}{\mathrm{Q}}$

$=\frac{0.00186 * 5.9 * 1.25 * 1.25 *(87+14.7)}{1.179}=1.479 \mathrm{sec}$

$$
1.179
$$

\section{Cylinder C:}

Gripping of crucible is achieved through pneumatic gripper Then the time taken for gripping is assumed to be $=0.3 \mathrm{sec}$

\section{Cylinder D:}

Function of cylinder D is to regulate the flow of molten metal

Cylinder D will be the rotary actuator which converts the linear motion to rotary motion

Time taken to pour $20 \mathrm{~kg}$ of molten metal $=45 \mathrm{sec}$

\section{Cylinder E:}

Function of cylinder $\mathrm{E}$ is to lift the core

$\mathrm{L}=300 \mathrm{~mm}=11.81 \mathrm{in}$

Force $=55 * 9.81=539.55 \mathrm{~N}$

Thrust force $\mathrm{P}=1.5 * \mathrm{~F}=1.5 * 539.55$

$$
=809.325 \mathrm{~N}
$$

$\mathrm{P}=\Pi / 4 * \mathrm{D} * \mathrm{~d} * \mathrm{p}$

$809.325=\Pi / 4 * \mathrm{D} * \mathrm{D} * 0.6$

$\mathrm{D}=41.44 \mathrm{~mm}=$ say $45 \mathrm{~mm}=1.73 \mathrm{in}$

$$
\mathrm{D}=2 \mathrm{~d}
$$

$1.73=2 * \mathrm{~d}$

$\mathrm{d}=0.866$ in

Forward stroke Tfs $=\underline{0.00186 * \mathrm{~L} * \mathrm{D} * \mathrm{D} *(\mathrm{P}+\mathrm{Pa})}$

$$
\text { Q }
$$

$$
\begin{gathered}
=0.00186 * 11.81 * 1.739 * 1.739 *(87+14.7) \\
1.179 \\
=5.3 \mathrm{sec}
\end{gathered}
$$

Return stroke Trs $=\underline{0.00186 * \mathrm{~L} *((\mathrm{D} * \mathrm{D})-(\mathrm{d} * \mathrm{~d})) *(\mathrm{P}+\mathrm{Pa})}$

$$
\begin{aligned}
& =\frac{0.00186 * 11.81 *((1.73 * 1.73)-}{1.179} \\
& =4.25 \mathrm{sec}
\end{aligned}
$$

\section{Cylinder F:}

There are 2 cylinders F1, F2 which are fixed to a T-joint. This cylinder is used to eject the pins

Assume $\mathrm{D}=1$ in

$$
\mathrm{d}=0.5 \mathrm{in}
$$

$$
\mathrm{L}=100 \mathrm{~mm}=3.9 \mathrm{in}
$$

Forward stroke Tfs $=\underline{0.00186 * \mathrm{~L} * \mathrm{D} * \mathrm{D} *(\mathrm{P}+\mathrm{Pa})}$

$$
=\frac{0.00186 * 3.9 * 1 * 1 *(87+14.7)}{1.179}
$$$$
=0.63 \mathrm{sec}
$$

Return stroke $\operatorname{Trs}=\frac{0.00186 * \mathrm{~L} *((\mathrm{D} * \mathrm{D})-(\mathrm{d} * \mathrm{~d})) *(\mathrm{P}+\mathrm{Pa})}{\mathrm{Q}}$

$=\frac{0.00186 * 3.9 *((1 * 1)-(0.5 * 0.5)) *(87+14.7)}{1.179}$

$=0.46 \mathrm{sec}$

\section{Cylinder G:}

Each die half has to drag a weight of $100 \mathrm{~kg}$

$$
\mathrm{L}=150 \mathrm{~mm}=5.9 \mathrm{in}
$$

Force $=100 * 9.81=981 \mathrm{~N}$

Thrust force $\mathrm{P}=1.5 * \mathrm{~F}=1.5 * 982=1471.5 \mathrm{~N}$

$\mathrm{P}=\Pi / 4 * \mathrm{D} * \mathrm{~d} * \mathrm{p}$

$1471.5=\Pi / 4 * \mathrm{D} * \mathrm{D} * 0.6$

$\mathrm{D}=55.88 \mathrm{~mm}=$ say $58 \mathrm{~mm}=2.28 \mathrm{in}$

$\mathrm{D}=2 \mathrm{~d}$

$2.28=2 * d$

$\mathrm{d}=1.14$ in

Forward stroke Tfs $=\underline{0.00186 * \mathrm{~L} * \mathrm{D} * \mathrm{D} *(\mathrm{P}+\mathrm{Pa})}$

$$
\mathrm{Q}
$$

$$
\begin{gathered}
=\frac{0.00186 * 5.9 * 2.28 * 2.28 *(87+14.7)}{1.179} \\
=4.92 \mathrm{in}
\end{gathered}
$$

Return stroke $\operatorname{Trs}=\frac{0.00186 * \mathrm{~L} *((\mathrm{D} * \mathrm{D})-(\mathrm{d} * \mathrm{~d})) *(\mathrm{P}+\mathrm{Pa})}{\mathrm{Q}}$
$\begin{aligned}=\frac{0.00186 * 11.81 *((2.28 * 2.28)-(1.14 * 1.14)) *(87+14.7)}{1.179} \\ =3.68 \mathrm{sec}\end{aligned}$

\section{Cylinder H:}

Cylinder $\mathrm{G}$ is used to grip or hold the core which is achieved with pneumatic gripper

Time taken for gripping (both forward and return stroke) $=0.2 \mathrm{sec}$

$\mathrm{T}_{\mathrm{fs}}=\frac{0.00186 * \mathrm{~L} * \mathrm{D} * \mathrm{D} *(\mathrm{P}+\mathrm{Pa})}{\mathrm{Q}}$ Seconds

Using the above cylinder's and PLC program,

The Total time taken $=$ cylinder $\mathrm{A}(\mathrm{FS})+$ cylinder $\mathrm{B}+$ cylinder C(GRIPPING) + POURING + SOLIDIFICATION + Time taken for cylinder $\mathrm{E}(\mathrm{FS}+\mathrm{RS})+$ cylinder $\mathrm{F}(\mathrm{FS}+\mathrm{RS})+$ cylinder $\mathrm{G}(\mathrm{RS}+\mathrm{FS})+$ cylinder $\mathrm{H}($ GRIPPING)+ Time for ejecting casting.

$2.76+1.47+0.3+45+45+5.3+0.2+4.2+4.92$

$+30+3.92+5.3+0.2+4.2+3.92$

$=152.53 \mathrm{sec}=2.54 \mathrm{~min}$ 
To ensure that our proposed system works correctly, the testing and simulation of the system has been performed. The majority of the testing proceedings were with the PLC program. The SEIMEN5 57-300 offers excellent assistance in the checking of the programming done on it. It has various tools for troubleshooting like display of the block status, simulation etc. The required operating sequence of the robot has been perfectly achieved by the use of PLC for its control. The timers were found to be working with desired range of accuracy. The testing was done on a trainer board, by using standard pneumatic cylinders, control valves and sensors, available in the market. The testing and simulation of the project was done at Automation and Robotics labs, Central Institute of Tool Design, Hyderabad with cylinders of following dimensions and given observations.

Table 1 Specifications of the cylinders utilized for the automation of the Gravity Die casting

\begin{tabular}{|c|c|c|c|c|}
\hline Cylinder & $\begin{array}{l}\text { Bore } \\
\text { Dia } \\
\text { (D) } \\
\text { Inch }\end{array}$ & $\begin{array}{l}\text { Length } \\
\text { of the } \\
\text { stroke } \\
\text { (L) Inch }\end{array}$ & $\begin{array}{l}\text { Time take } \\
\text { for forward } \\
\text { stroke }\left(\mathrm{T}_{\mathrm{fs}}\right) \\
\text { in } \mathrm{Sec}\end{array}$ & $\begin{array}{l}\text { Time taken } \\
\text { for } \\
\text { backward } \\
\text { stroke }\left(T_{\mathrm{rs}}\right) \\
\text { Sec }\end{array}$ \\
\hline A & 1.4 & 11.81 & 2.76 & - \\
\hline $\mathrm{B}$ & 1.25 & 5.9 & 1.479 & - \\
\hline $\mathrm{C}$ (gripping) & - & - & 0.3 & - \\
\hline $\mathrm{D}$ (pouring) & - & - & 45 & - \\
\hline $\mathrm{E}$ & $\begin{array}{l}1.73 \\
9\end{array}$ & 11.81 & 5.3 & 4.25 \\
\hline $\begin{array}{l}\mathrm{F} \text { (pin } \\
\text { ejection) }\end{array}$ & 1 & 3.9 & .63 & .46 \\
\hline $\mathrm{G}$ & 2.28 & 5.9 & 4.92 & 3.68 \\
\hline $\mathrm{H}$ & - & - & 0.2 & \\
\hline
\end{tabular}

\section{CONCLUSION}

The approach of Low cost automation particularly in small scale industries with the usage of simple devices like Pneumatic and Hydraulic actuators with electrical control to the existing conventional methods will make them automatic at low cost to yield higher productivity for stability and growth of economy. By automating the process we can reduce the effort of the operator and hence time is saved which can be used for decision making. Automating Casting process using PLC is not only economical but also time saving.The total time taken is far less than the time taken in traditional methods. Programming a PLC requires less skill and maintenance, therefore will be flexible enough for any changes.

\section{REFERENCES}

[1]. Mohan Yashvant Khire, S.D. Madnaik ., Folding cartons using low cost automation - a case study., Assembly Automation., Vol: 21, pp: 210 - 212., MCB UP Ltd 2001.

[2]. Vivek A. Bandebuche, D. J. Tidke "Parts Handling Systems for Machine Shops of Small and Medium Enterprises", Proceedings of the 14th IEEE international conference on Emerging technologies \& factory automation, p.1221-1225, September 22-25, 2009, Palma de Mallorca, Spain

[3]. Groover M. P., Automation, Production Systems, and Computer Integrated Manufacturing, 3rd Edition: PHI 2008.

[4]. Ahuja D., Chaudhary N., " Programmable Logic Controller," In International Journal Of Information And Computer Science, 2012

[5]. S. Joe Qin, and Thomas A. Badgwell; "A survey of industrial model predictive control technology", Control Engineering Practice 11 pp. 733-764 (2003)

[6]. K. Furuta, "Super mechano-systems: fusion of control and mechanism", plenary paper, Prepr. 15th IFAC World Congress, (Volume with Plenary Papers, Survey Papers and Milestones), Barcelona, Spain (2002) pp. 35-44.

[7]. IEC International Standard 1131-3, Programmable Controllers, Part 3, Programming Languages, 1993.

[8]. Teresa Deveza , J. F. Martins, PLC control and Matlab/Simulink simulations: a translation approach, Proceedings of the 14th IEEE international conference on Emerging technologies \& factory automation, p.1221-1225, September 22-25, 2009, Palma de Mallorca, Spain

[9]. S. Brian Morriss, Automated Manufacturing Systems: Actuators, Controls, Sensors, and Robotics, Glencoe/McGraw-Hill, 1994

[10]. SHOJIMA TOSHIKI(Idemitsu Kosan Co., Ltd., Chiba Refinery, JPN ., Application of low cost automation in refinery off-site job (No.3)., Application of DCS control ,Idemitsu Technical Report . VOL : 46 ; pp: 123-128., 2003.

[11]. M. Chmiel, E. Hrynkiewicz, M. Muszynski, "The way of ladder diagram analysis for small compact programmable controller", Proceedings of the 6th RussianKorean International Symposium on Science and Technology KORUS-2002, pp. 169-173, 2002. 